\title{
Accounting
}

\section{Accounting and features of mathematical modeling of the system to forecast cryptocurrency exchange rate}

\author{
Tetiana Tarasova ${ }^{a}$, Olga Usatenko ${ }^{b}$, Andrii Makurin ${ }^{b}$, Valentyna Ivanenko ${ }^{\mathrm{c}}$ and Anzhela \\ Cherchata ${ }^{*}$
}

${ }^{a}$ Kharkiv State University of Food Technology and Trade, Ukraine

${ }^{b}$ Dnipro University of Technology, Ukraine

${ }^{c}$ Zhytomyr State Technological University, Ukraine

${ }^{d}$ State Higher Educational Institution «Pridneprovsk State Academy of Civil Engineering and Architecture»

\begin{tabular}{l}
\hline C H R O N I C L E \\
\hline Article history: \\
Received November 232019 \\
Received in revised format \\
November 292019 \\
Accepted January 152020 \\
Available online \\
January 172020 \\
\hline Keywords: \\
Cryptocurrency accounting \\
Intangible asset \\
Information \\
Stablecoin \\
Cryptocurrency exchange \\
Instability
\end{tabular}

\section{A B S T R A C T}

The objective of this paper is to determine the basic features of the use of mathematical modeling of the system to forecast cryptocurrency exchange rate. The study determines that cryptocurrency is the simplest investment asset being and, at the same time, the riskiest one. Advantages and disadvantages of cryptocurrency use are specified. Advantages include: code openness, anonymity, decentralization, emission, and reliability. Disadvantages include lack of guarantees, instability, risk of prohibition and possible loss. A model to forecast bitcoin cryptocurrency exchange rate is proposed and substantiated mathematically. The observations are the basis to develop a hypothesis: the faster the cryptocurrency (e.g. bitcoin) is mined, the more difficult it is to forecast bitcoin cryptocurrency exchange rate. Certain factors emphasize which may affect the cryptocurrency exchange rate: trade wars of the USA with other export-oriented world economies (China); advent of IEO as the alternative for ICO and new drivers connected with the interest in cryptocurrency; FATF recommendations for market control, the entry of world giants (e.g. Facebook) into the crypto-market and the development of the stablecoin market.

C) 2020 by the authors; licensee Growing Science, Canada

\section{Introduction}

Use of the digital computing tools to process scientific, economic, and social information has changed the human capacity, considerably. Virtual space is being activated year over year being the result of efficient application of information resources. Currently, people live in dual lives: the first life is real while the second one is virtual. People's attitude to real money is changing as well. More and more often the humanity uses electronic money, electronic wallets, and specific modern phenomenon intangible asset represented by "cryptocurrency". Nowadays, owing to the virtual space, information is one of the key economic resources; and access to the World Wide Web has made us to assess constantly the value of the obtained information which depends on its topicality level. The obtained data should be reliable and accurate since it affects considerably the formation of market circumstances. Reliable information helps control the market situation; moreover, if there is the possibility to have real influence on that information and change it for one's own benefit, it allows reducing the probability of adverse consequences in the future. Cost of assets at an enterprise is being constantly assessed and changed according to the certain date of balancing and time interval. In other words, value is recorded relative to certain date and hour. Phenomenon of modern digital money in

* Corresponding author

E-mail address: anzhela_cherchata@ukr.net (A. Cherchata) 
the form of cryptocurrency is at the same time the least researched and the simplest investment asset. More and more people are paying attention to cryptocurrency investing in and hoping to get passive income, which is not subject to income tax in Ukraine. Investing in cryptocurrency is rather risky. Nevertheless, the majority of people take risk and invest in cryptocurrency seeing it as the potential for their gaining. Cryptocurrency trades attract more and more speculators - either novices in trading operations or those who have experience of stock or national currency trading. It is possible to evaluate dynamic conditions of income correlation between cryptocurrency and traditional assets using DCC (there is the direct information exchange without any server). Investment portfolios are built according to classic impulse strategy using everyday data on twelve cryptocurrencies within the period of three years. Cross correlations of weekly income between the portfolio of cryptocurrencies impulses and traditional assets are not stable. Portfolio of cryptocurrencies impulses does not only propose diversification advantages but also it may be the protection against the depreciation for traditional assets (Tzouvanas et al., 2019). Considerable liquidity of digital currency results in the development of the growing number of cryptocurrencies. Nowadays, the market contains more than a thousand of tokens of different cryptocurrencies. However, the majority of cryptocurrencies are not in demand since they do not differ technically from their predecessors and have poor capitalization. Exchange rate of new cryptocurrencies depends mostly on the marketing making it possible to forecast their rate involving analysis of internal or external factors. Value of cryptocurrency and its exchange rate relative to any traditional asset may be forecasted. To do that, it is required to use mathematical modeling of the system of exchange rate forecast involving Microsoft Excel environment (Shen et al., 2019).

\section{Literature review}

Many scientists have been engaged in solving the problem of cryptocurrency exchange rate forecast using mathematical methods; in particular, Pieters and Vivanco (2017) define considerable differences in bitcoin prices at 11 different cryptocurrency exchanges making up almost $26 \%$ of world total of that asset trading. It is specified that in terms of the market not requiring client identification to open account, deviation from the representative market prices occurs faster. Bouri et al. (2019) have developed their own dynamic correlation model to study the issue whether bitcoin may be used as hedging or it will become safe haven for main world stock indices, bonds, oil, gold, or general commodity index and USD index. It is determined that bitcoin is poor hedge being appropriate only for diversifications. However, bitcoin may be only the safe haven against extreme weekly falls in Asian stocks. Feng et al. (2018) evaluate price sensitivity of bitcoin in terms of political and economic events; they define that information trading is rather profitable for the cryptocurrency market. They propose new index to assess informed trades before the events connected with cryptocurrency. Phillip et al. (2018) specify that bitcoin rate makes up and unites numerous diverse identified facts including long-term memory and heteroscedasticity (dense range for generalization of a linear model). The scientists unite numerous attributes into one mathematical model to assess investment attractiveness of cryptocurrency. They have determined that, in general, cryptocurrency has several unique features including leverage effect and error distribution effect. Tzouvanas et al. (2019) have analyzed more than 120 events from five clusters to check compliance with the regulatory basis for cryptocurrency value. They have identified that the evaluations within the market environment and estimations for 300 separate coins demonstrate statistically and economically considerable counteracting effect to money laundering and money emission control. Katsiampa et al. (2019) study interaction between information demand measured by means of Google search index, price returns, and trade volumes for five basic cryptocurrencies. Shen et al. (2019) analyze interaction between the investors' attention and Bitcoin profitability, trade volumes and implemented instability. Pastrana and Suarez-Tangil (2019) investigate illegality of certain types of cryptocurrency operations and proved possibility of their evening-out. Hong et al. (2018) prove that cryptocurrency mining grows in its popularity. Chen and Ko (2019) show that Blockchain-wallet plays essential role in blockchain industry; and offer a cryptocurrency blockchain-wallet which is integrated with augmented reality and crypto-technology, i.e. augmented cryptocurrency (CryptoAR Wallet). Adhami et al. (2018) describe the phenomenon of Initial Coin Offering (ICO), which made it possible for startups to collect more than USD 5.3 billion before the end of 2017 worldwide. They also demonstrate that success probability for ICO is even higher if the code source is accessible when advance sale of tokens is organized and when markers helps participants access certain service (or for income distribution). Yiying and Yeze (2019) claim that cryptocurrency is gaining its importance in reformatting financial system owing to its rising popularity. Nabilou and Prüm (2019) state that cryptocurrencies affect significantly banking, financial, and monetary systems. Adamik and Kosta (2019) develop decentralized exchange solution based on the reasonable contracts operating within the Ethereum network being close and tested and not requiring trust. Lukyanov (2014) believes that cryptocurrency is the symbol of information money, which is now competing with traditional paper money, and substantiates the fact that cryptocurrency is the attribute of global matrix of information era. Baur et al. (2015) consider cryptocurrencies as potentially destroying means of payment. Among Ukrainian scientists, Petruck and Novak (2017) should be mentioned who study the essence of cryptocurrency and analyze features of accounting representation of such an asset. Derun and Skliaruk (2018) study issues of cryptocurrency classification analyzing its signs and types. The authors analyze a model of decentralized cryptocurrency schemes and reveal their basic characteristics. Fostolovich (2018) researches problems of digital information space and necessity to solve problems of accounting and taxation of cryptocurrency operations. Augustova (2018) examines economic and legal cryptocurrency essences and studies stages of world conquering by cryptocurrency. She also proposes to define cryptocurrency as a virtual currency and put it equal to payment means of the economic entities. Studying the problem of accounting of cryptocurrency 
value, dependence between the cryptocurrency exchange rate and, for instance, adopted decision in People's Republic of China (as for the prohibition of "mining" in the northern part of the country due to considerable electric power consumption) is defined. Currently, there are three key tendencies to forecast currency exchange rate, i.e.: technical analysis, fundamental analysis, and analysis of economic cycles (Kornieiev \& Cheberiako, 2018; Safiullin et al., 2018). Cryptocurrency has appeared owing to the use of certain technology such as blockchain which makes it possible to exchange resources in electronic form. The idea of implementation and application of such asset as cryptocurrency is stipulated by the elimination of the participation of controlling parties to support certain liveness of the developed infrastructure (Kinash et al., 2019; Andrusiv et al., 2020; Shanaev et al., 2020). At the same time, there is a possibility to exchange resources between the unknown people who do not trust each other. That is possible because accounting of cryptocurrency transactions is transferred from the centralized system to the decentralized one developed with the help of autonomous computers (in terms of Ukraine, that is NBU, VRU, and President). In terms of that system, cryptocurrency auditing is constant being unchangeable and public; it is constantly controlled through the network of independent computers (Fedorova, 2018). Reasonable investments in cryptocurrency may bring considerable dividends. To make money out of cryptocurrency trading, one should know how to forecast correctly future movement of cryptocurrency price. Thus, it is required to define basic parameters and factors effecting the cryptocurrency rate forecast. The Objective of the paper is to define key features of the use of mathematical modeling of the system to forecast cryptocurrency rate.

\section{Results}

Cryptocurrency has rather floating exchange rate to the national currencies and their types. Thus, stablecoin has entered the financial cryptocurrency market; stablecoin is cryptocurrency but its value depends on the value of traditional financial assets. Traditional financial assets include US dollar, oil, natural gas, and gold. Cryptocurrency rate pegging to the value of such an asset is the attempt to adapt digital technology to the real life. That makes it possible to use Stablecoin as the payment instrument in the exchange relationships since that helps determine and compare prices for goods and services. The available stablecoins may be divided into three types. Type one includes stablecoins backed with the traditional currencies and other assets. For instance, in terms of a dollar, digital tokens are issued in one-to-one correlation. Type two includes stablecoins backed with other cryptocurrencies. Such stablecoins and their value depend on the advanced cryptocurrencies, e.g. Bitcoin and Ethereum. Such a scheme has higher risk as the cryptocurrency crash may depreciate that stablecoin. Type three includes stablecoins which are not backed. Such coins differ from the standard cryptocurrencies in the fact that in terms of smart-contracts, automatic increase or reduction of the supply to control the price is used; the process is similar to the Central Bank operation. One of the stablecoins feature is that they are impossible to be "mined"; they may be obtained only after their conversion at the exchange market. The most popular stablecoins are represented in the form of Tether (USDT) or "digital dollar"; Didig (DGX) or "digital gold"; El Petro or "digital oil". Nowadays, development in digital technology affects the changes not only in the technologies dealing with goods and service payment operations but also people's attitude to that process (Ievdokymov et al., 2020). One generation replaces another, modern society experiences constant transformations. Since the ancient time, people got used to real money, which may be kept in their own pocket or wallet. Such money was made from precious metals; later, it was replaced with "paper money". With the advances in information technology, humanity began to use electronic money and open their electronic wallets using WebMoney and Qiwi resources. The majority of modern generation use Privat24 and PayPal services. Such technological development has simplified considerably processes of shopping, utility payments, account top-up etc. However, our society consists of different generations with different ideas based on their upbringing and education. Not all the people understand modern technologies and use them in their everyday life. Bitcoin is considered to be the first cryptocurrency because the algorithm of its operation was described in 2008. Certain technical aspects of that currency functioning were represented. In January 2009, cryptocurrency code appeared with no access restrictions; and in September 2009, first data block for that currency was developed.

American scientists Strauss and Howe (2000) represented their book entitled as "Generations" where they demonstrated life cycles of different generations. According to their ideas, the Greatest Generation lived within the period of 1900-1923 being replaced by the Silent Generation (1923-1943) who were succeeded by the Baby Boom Generation (1943-1963). End of the Generation X (1963 - 1983) was marked by the origin of information technology era connected with a personal computer represented by the IBM company on 12 August, 1981. Then came the Generation Y (millennials) from 1983 to 2003 and the Generation Z (from 2003 up to now). Chaum (1983) tried to develop the system which would be transparent for all the market participants and represented the payment anonymity at the same time. Actually, those were the first steps to found a system with "blind signatures" to use electronic cash. The richest people in the world established Google, Tesla, Amazon, and Space - all of them were the representatives of the Generation X. That was not just a coincidence - " $\mathrm{X}$ " generations were born before the Internet advent (1980) which effected the events and advantages in the Internet. Millennials are children of the Generation X and grandchildren of the Baby Boom Generation. In other words, not all the living and still active generations use credit cards, connected to the MasterCard or Visa systems of leading banks, instead of "paper money". Most people perceive cryptocurrency as something vague and strange being fearful of it. Any currency should encourage consumers to make purchases and simplify payments. Current digital currencies, such as bitcoin, use one-range networks and open-code software to make end transactions. Use of cryptocurrency during payments may be considered as a challenge for accounting. While using cryptocurrency, it is 
impossible to identify from whom and to whom the monetary means are being transferred. The main task here is to form complete and reliable information for inquiry of different users. That creates certain restrictions to understand the participants paying for different goods, operations, and services. Trading at cryptocurrency exchange markets is organized on the twentyfour-hour basis. Most traders and brokers emphasize that average monthly instability of bitcoin profitability is higher than in terms of gold. Generations $\mathrm{Y}$ and $\mathrm{Z}$ pay great attention to investment in such specific assets, because millennials not only use their monetary means in different way; their investment habits also experience constant changes. Generation $Y$ uses technology which alters its investment habits. According to the data by Accenture UK consulting, $67 \%$ of millennials want to use roboticsbased services. At the initial stage, a user specifies his/her objectives, and Betterment recommends him/her a sum to be invested with further automatic selection of the plan with the risk identification (Dwyer, 2015). The service changes regularly the portfolio balance, which support uniform risks and reinvest automatically the received dividends. Nowadays, cryptocurrency is the simplest way to invest in; however, there are considerable risks as well. Analyze the approaches to stablecoin investment, which is compared with electronic gold, and determine key positive and negative features of cryptocurrency and stablecoin use. Code openness is the advantage of the cryptocurrency and stablecoin use. That features ensure the equality of all the network participants. The system is transparent and clear for every participant who wants to mine coins. Next feature is anonymity. It is not simple to find information about the owner of a cryptocurrency wallet. In the ideal case, you can only know the wallet address and transaction data. More advanced cryptocurrencies (Monero, ZCash) even provide transaction anonymity. Main feature differing cryptocurrency from the usual monetary means is decentralization. Cryptocurrency is independent from the third party interference. Cryptocurrency emission as well as transactions is controlled by the program code, which is open and installed in all the computer networks. Next feature demonstrates the rule of cryptocurrency emission, i.e. there is certain limitation due to the use of mathematical rules, which include inflation depending on the emitter activity. In the digital world, great attention is paid to reliability. Currently, it is considered to be impossible to break or split transactions. For instance, targetfinancing operations involving cryptocurrency transferred as information blocks help understand whether a customer receives the total sum and what objectives and what amount of the sent finances are, since cryptocurrency leaves certain "virtual prints". Such problems with non-target use of monetary means and ways of their solution were proposed in terms of coal mining industry (Petruk \& Makurin, 2015) as the dotation level in this industry is considerably higher (consequently, corruption is rather possible) comparing to other economic industries in Ukraine. Disadvantages of the cryptocurrency and stablecoin use are represented by the lack of certain guarantees and high risks, i.e. each user is responsible for his/her wallet since there are no controlling institutions and agencies. It is impossible to appeal to a court if someone steals access code for your wallet. Considerable instability of cryptocurrency prevents investors from investing in it. Thus, if it is required to save your finances, it is reasonable to use first type of stablecoins, which are backed with traditional financial assets. There is also a risk connected with prohibition of cryptocurrency use at the state level. Some countries have introduced restrictions for its use. Next risk is possibility of cryptocurrency loss. Access to electronic money may be changed by means of special key. If that key is lost, we will never be able to access our money.

\section{Table 1}

Advantages and disadvantages of cryptocurrencies

\begin{tabular}{cccc}
\hline$№$ & Advantages of cryptocurrency & Disadvantages of cryptocurrency & Advantages of stablecoins \\
\hline 1 & code openness & lack of guarantees & Disadvantages of stablecoins \\
2 & anonymity & instability & dependence on the fiat money \\
3 & decentralization & risk of prohibition & global digital currency \\
4 & limitation & risk of loss & \\
5 & reliability & & necessity in intermedia \\
\hline
\end{tabular}

* formed by the authors based on their own research

To forecast the exchange rate of traditional currencies, technical analysis, fundamental analysis, and analysis of economic cycles are used. On the Internet, different companies propose services concerning short-term and long-term forecast of cryptocurrency rate (Khalimonchuk, 2018). However, none of them offers the forecast methods since that is the commercial secret. Scientific community shares the idea that the value of "virtual coins" is defined in a market-oriented way. Increasing demand for certain cryptocurrency increases its exchange rate. In its turn, the demand depends on those advantages, which the coin proposes. If costs for bitcoin mining will be accepted in China and the bitcoin will be the official currency for payments, then bitcoin value will increase in algebraic progression. Factor of interest will come into action - the more people know about the product, the more people want to invest their money in it or control and possess it. For instance, if only demand affects the exchange rate forecast, then there is a quantitative evaluation of that demand. Then, it may be concluded that further demand influences the pricing, i.e. conclusion on the demand of some cryptocurrency may be drawn with the help of such scientific method as observation. One can also define the fact how often the cryptocurrency-related topics are discussed on the Internet or how Internet-users are interested in searching for cryptocurrency-related materials using Goggle search engine ("bitcoin rate cash", "coin binance"). Moreover, it is possible to analyze how many cryptocurrency-related posts Facebook or Twitter contain. Such an approach has following advantages: the index is quantitative; the index is technically accessible for calculation; such approach is simple to use; connection between demand and forecasted cryptocurrency exchange rate is clear. 
Thus, solution of such formal mathematical model may be represented in the form of Eq. (1) - forecast of bitcoin cryptocurrency rate.

$$
B=\left\{\begin{array}{c}
\mathrm{B}^{1} *\left(d B\left(d-d_{f}\right)\right) ; \\
B *\left(d-d_{f}-1\right) ; \\
B *\left(d-d_{f}-d_{m 1}\right)
\end{array} \quad G=\left\{\begin{array}{c}
G *\left(d-d_{f}\right) \\
G *\left(d-d_{f}-1\right) \\
G *\left(d-d_{f}-d_{m 2}\right)
\end{array}\right.\right.
$$

where,

$\mathrm{B}^{1}$ is forecasted cryptocurrency exchange rate (bitcoin);

$\mathrm{d}$ is amount of days spent for forecasting;

$\mathrm{B}$ is real cryptocurrency exchange rate (bitcoin) per date;

$\mathrm{d}_{\mathrm{f}}$ is day of forecasted events;

$\mathrm{d}_{\mathrm{m} 1}$ is sampling of days in terms of exchange rate forecasting;

$\mathrm{d}_{\mathrm{m} 2}$ is number of days in terms of which data from Google search engine are obtained.

Elaboration of the mathematical model to forecast cryptocurrency exchange rate is not studied enough. Nevertheless, it has certain similarities with the forecast of real exchange rate of traditional currencies (Fig. 1). Solution of that forecast problem is represented in the form of commercial service which does not reveal the details of the applied instruments. Effect of the Internet users' interest is rather considerable. Observations over the users mining the cryptocurrency have made it possible to draw the following conclusion: the faster cryptocurrency (e.g. bitcoin) is mined, the more complex mining is. That has partial effect on the exchange rate level as well. It means that there is the dependence: the higher complexity is, the higher rate is. There is also another hypothesis: complexity and cryptocurrency hashrate increase along with its price since the market becomes more favorable with the growing number of miners. The developers introduce limitations for coin mining dealing with the mining complexity. The more popular the coin is, the more miners are interested in its mining: they connect computing facilities to the network increasing its hashrate; thus, they make mining to be more complicated (Table 2).

Table 2

Factors influencing the cryptocurrency exchange rate

\begin{tabular}{cccccc}
\hline Period number, & Metric value, & Number of network members $(\mathrm{pcs})$ & Difficulty level $(\mathrm{t})$ & Network & Power \\
\hline 12.10 .2019 & 7477 & accurate data cannot be obtained & 6.3 & 56 \\
15.10 .2019 & 7944 & accurate data cannot be obtained & 6.5 & 56 \\
18.10 .2019 & 8177 & accurate data cannot be obtained & 6.6 & 57 \\
21.10 .2019 & 8220 & accurate data cannot be obtained & 6.9 & 58 \\
24.10 .2019 & 8374 & accurate data cannot be obtained & 8 & 58 \\
27.10 .2019 & 8809 & accurate data cannot be obtained & 10 & 59 \\
30.10 .2019 & 9362 & accurate data cannot be obtained & 12 & 60 \\
02.11 .2019 & 9608 & accurate data cannot be obtained & 12.5 & 62 \\
05.11 .2019 & 9906 & accurate data cannot be obtained & 13.7 & 65 \\
22.11 .2109 & 7367 & accurate data cannot be obtained & 8.8 & 60 \\
01.12 .2019 & 7351 & accurate data cannot be obtained & 8.1 & 62 \\
15.12 .2019 & 7140 & accurate data cannot be obtained & 7.8 & 64 \\
31.12 .2019 & 7600 & accurate data cannot be obtained & 7.6 & 60 \\
\hline
\end{tabular}

* formed by the authors based on their own research

\section{Conclusions}

Many investors have felt anomalous fluctuation levels of cryptocurrency investment indices within different periods of market cycles. Though instability may be more intense then it was predicted during certain periods of time, a conclusion may be made on the fact that the typical method to measure instability favors the problem of unpredicted instability. It is proposed to take into consideration the factors, which may also affect the cryptocurrency exchange rate:

- $\quad$ Trade wars of the USA with other export-oriented world economies (China);

- $\quad$ Advent of IEO as the alternative to ICO and new drivers connected with the interest in cryptocurrency; 
- $\quad$ FATF recommendations to control the market;

- $\quad$ Entry of world giants into crypto-market (e.g. Facebook);

- $\quad$ Development of the stablecoin market.

Thus, it is quite real to forecast the exchange rate movement basing on the network complexity and the amounts of participants; however, such an approach is rather unreliable. Actually, the rate is affected by the totality of certain factors, and there should be comprehensive analysis anyway: number of transactions in a mempool, halving, trade volume, technical and fundamental factors, news, number of new wallets.

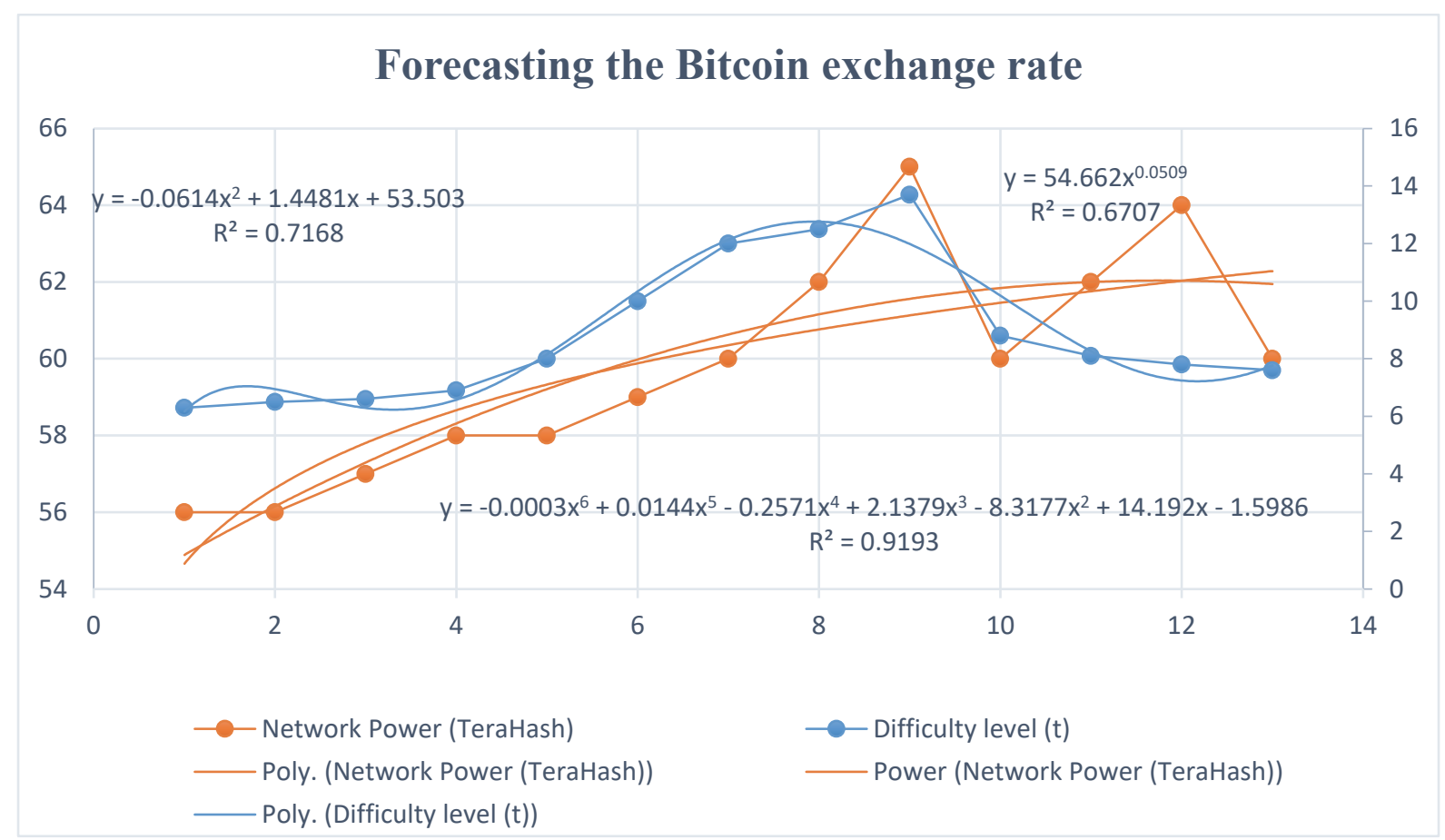

Source: the author's development

Fig. 1. Forecasting the Bitcoin rate

\section{Acknowledgement}

The authors would like to thank the anonymous referees for constructive comments on earlier version of this paper. 
Adamik, F., \& Kosta, S. (2019). Smartexchange: Decentralised trustless cryptocurrency exchange. International Conference on Business Information Systems, 356-367. doi:10.1007/978-3-030-04849-5_32

Adhami, S., Giudici, G., \& Martinazzi, S. (2018). Why do businesses go crypto? an empirical analysis of initial coin offerings. Journal of Economics and Business, 100, 64-75. doi:10.1016/j.jeconbus.2018.04.001

Andrusiv, U., Kinash, I., Cherchata, A., Polyanska, A., Dzoba, O., Tarasova, T \& Lysak, H. (2020). Experience and prospects of innovation development venture capital financing. Management Science Letters , 10(4), 781-788.

Augustova, O. (2018). Economic content of cryptocurrency and its accounting in Ukraine. Economy and Society, 18, 844-849.

Baur, A. W., Bühler, J., Bick, M., \& Bonorden, C. S. (2015). Cryptocurrencies as a disruption? empirical findings on user adoption and future potential of bitcoin and co. International Conference on Business Information Systems, 6380. doi:10.1007/978-3-319-25013-7_6

Bouri, E., Molnár, P., Azzi, G., Roubaud, D., \& Hagfors, L. I. (2017). On the hedge and safe haven properties of Bitcoin: Is it really more than a diversifier?. Finance Research Letters, 20, 192-198.

Chaum, D. (1983). Blind signatures for untraceable payments. Advances in cryptology. Springer, Boston, MA, 199-203.

Chen, Y. P., \& Ko, J. C. (2019, October). CryptoAR Wallet: A Blockchain Cryptocurrency Wallet Application that Uses Augmented Reality for On-chain User Data Display. In Proceedings of the 21st International Conference on HumanComputer Interaction with Mobile Devices and Services (pp. 1-5).

Derun, I. \& Sklyaruk, I. (2018). The ontological aspects of the essence of cryptocurrency and its display in accounting. Scientific notes of Ostroh Academy National University. Economics series: Scientific journal, 11(39), 163-170.

Dwyer, G. (2015). The economics of Bitcoin and similar private digital currencies. Journal of Financial Stability, 17, 81-91.

Fedorova, Y. (2018). Crypto currencies and their place in the financial system. Economy and society, 15, 771-774.

Feng, W., Wang, Y., \& Zhang, Z. (2018). Informed trading in the Bitcoin market. Finance Research Letters, 26, 63-70.

Fostolovich, V. (2018). The mechanism of cryptocurrency management in the enterprise accounting system. Effective Economics, 5, Available at: http:// http: www.economy.nayka.com.ua/

Hong, G., Zhang, L., Yang, M., Yang, Z., Nan, Y., Zhang, Y., . . ., \& Qian, Z. (2018). How you get shot in the back: A systematical study about cryptojacking in the real world. Paper presented at the Proceedings of the ACM Conference on Computer and Communications Security, 1701-1713. doi:10.1145/3243734.3243840

Ievdokymov, V., Lehenchuk, S., Zakharov, D., Andrusiv, U., Usatenko, O \& Kovalenko, L. (2020). Social capital measurement based on "The value explorer" method. Management Science Letters, 10(6), 1161-1168. doi: 10.5267/j.msl.2019.12.002

Katsiampa, P., Moutsianas, K., \& Urquhart, A. (2019). Information demand and cryptocurrency market activity. Economics Letters, 185. doi:10.1016/j.econlet.2019.108714

Kinash, I., Andrusiv, U., Golovnia, O \& Popadynets, I. (2019). Aspects of the formation and development of innovation infrastructure in Ukraine. Management Science Letters, 9(13), 2403-2414. doi: 10.5267/j.msl.2019.7.015

Kornieiev, V. \& Cheberiako, O (2018). Crypto currencies: The Age and Sphere of Financial Innovation. Bulletin of the Kiev National University. Taras Shevchenko. Series: Economics, 196(1), 40 - 46.

Lukyanov, V. S. (2014). Cryptocurrency market establishment within information network paradigm. Actual Problems of Economics, 158(8), 436-441.

Nabilou, H., \& Prüm, A. (2019). Ignorance, debt, and cryptocurrencies: The old and the new in the law and economics of concurrent currencies. Journal of Financial Regulation, 5(1), 29-63. doi:10.1093/jfr/fjz002

Pastrana, S., \& Suarez-Tangil, G. (2019). A first look at the crypto-mining malware ecosystem: A decade of unrestricted wealth. Paper presented at the Proceedings of the ACM SIGCOMM Internet Measurement Conference, IMC, 73-86. doi: $10.1145 / 3355369.3355576$

Petruck, O. \& Novak, O. (2017). The essence of cryptocurrency as a methodological premise of its accounting display. Bulletin of Zhytomyr State Technological University. Series: Economics, Management and Administration, 4(82), 48-55.

Petruk, O. \& Makurin, A. (2015). Accounting and analytical problems at coal-mining enterprises of Ukraine in terms of European integration. Economic Journal, 21(9-10), 111-114.

Phillip, A., Chan, J. S. K., \& Peiris, S. (2018). A new look at Cryptocurrencies. Economics Letters, 163, 6-9.

Pieters, G., \& Vivanco, S. (2017). Financial regulations and price inconsistencies across Bitcoin markets. Information Economics and Policy, 39, 1-14.

Safiullin, M., Abdukaeva A., \& Elshin L. (2018). Methodological approaches to forecasting the dynamics of the cryptocurrency rate using stochastic analysis tools (using Bitcoin as an example). Finance: Theory and Practice, 22(4), 38-51.

Shanaev, S., Sharma, S., Ghimire, B., \& Shuraeva, A. (2020). Taming the blockchain beast? Regulatory implications for the cryptocurrency Market. Research in International Business and Finance, 51, 101080.

Shen, D., Urquhart, A., \& Wang, P. (2019). Does twitter predict bitcoin? Economics Letters, 174, 118-122. doi:10.1016/j.econlet.2018.11.007

Shen, D., Urquhart, A., Wang, P. (2019). A three-factor pricing model for cryptocurrencies. Finance Research Letters, $52-60$. Strauss, W. \& Howe N. (2000). Millennials rising: The next great generation. New York: Vintage Books, . 29. 
Tzouvanas, P., Kizys, R., Tsend-Ayush, B. (2019). Momentum trading in cryptocurrencies: Short-term returns and diversification benefits. Economics Letters, 108728.

Yiying, W., \& Yeze, Z. (2019). Cryptocurrency price analysis with artificial intelligence. Paper presented at the 5th International Conference on Information Management, ICIM 2019, 97-101. doi:10.1109/INFOMAN.2019.8714700

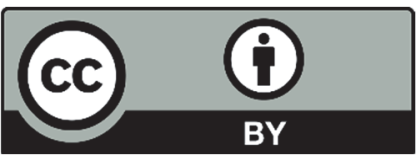

(C) 2020 by the authors; licensee Growing Science, Canada. This is an open access article distributed under the terms and conditions of the Creative Commons Attribution (CC-BY) license (http://creativecommons.org/licenses/by/4.0/). 